\title{
AN ECOLOGICAL TREATMENT METHOD FOR IFOSFAMIDE CONTAMINATED WASTE WATER RESULTING FROM ONCOLOGICAL THERAPY
}

\author{
VALENTIN ORDODI ${ }^{a, b,{ }^{*}}$, ANA-MARIA PANÄ ${ }^{a,{ }^{*}}$, ALINA DUMITREL ${ }^{a, \#,}$ \\ DANIEL HĂDĂRUGĂ ${ }^{a}$, ANDRA TĂMAȘ ${ }^{a}$, VASILE PODE ${ }^{a}$, \\ ANAMARIA TODEA ${ }^{a}$, VIRGIL PĂUNESCỨ $^{c}$, ȘERBAN NEGRU ${ }^{c}$
}

\begin{abstract}
Ifosfamide is a potent alkylating agent used to treat many forms of human cancer. Exposure to this substance for the long term even in small quantities has serious negative effects on human health and the environment. This study presents an ecological method of electrochemical inactivation of ifosfamide in an automatic laboratory installation. The neutralization process consists of ifosfamide electrochemical and chemical oxidation via reactive chlorine species generated in situ at the anode of the electrochemical reactor with asymmetric current densities. The neutralization efficiency of ifosfamide using this method is approximately $99 \%$ if the duration of the electrodegradation process under the presented conditions is 30 minutes.
\end{abstract}

Keywords: electrochemical wastewater treatment, ifosfamide, electrooxidation, asymmetric current density reactor

\section{INTRODUCTION}

In recent years, the problem of eliminating liquid waste from medical institutions by ecological methods has become increasingly acute. In most cases, incineration is not a viable solution for this category of waste due to the very large volumes, and at the same time, during incineration process a series of chemical compounds harmful to the environment are generated $[1,2]$. Medical units with an oncological profile generate large amounts of liquid waste

\footnotetext{
a Politehnica University of Timișoara, 2 Victoriei Square, RO-300006, Timișoara, Romania

b SC Natural Ingredients R\&D SRL, Tabacari Street, No. 10/1, RO-505200, Făgăraș, Romania

c University of Medicine and Pharmacy “V. Babeș” Timișoara, 2 Eftimie Murgu Square RO-300041, Timișoara, Romania

* These authors Contributed equally to this paper.

\# Corresponding author: alina.dumitrel@upt.ro
} 
(i.e. patients' urine) that often contains significant amounts of cytostatic drugs either unmetabolized or metabolized into other species with cytotoxic, mutagenic, carcinogenic and teratogenic activity. In 1996, the International Agency for Cancer Research (IARC) proposed the use of chemical treatments with oxidizing agents, acids or bases for the neutralization of cytostatic wastewater [3,4].

Nowadays, hematooncology is increasingly using high-dose cytostatic therapies associated with stem cell transplantation in order to save a large proportion of patients who until recently were considered incurable. Ifosfamide is one of the most commonly used cytostatic drugs in these treatments, administrated in high-doses per day from which approximately $50 \%$ is excreted unchanged in patients' urine $[5,6]$.

The aim of this current study is the design and testing of an automated laboratory installation that allows inactivation of ifosfamide content from contaminated wastewater by chemical and electrochemical oxidation in a reactor with asymmetric current densities $[7,8]$. In the literature, electrochemical methods are used relatively frequently to remove hazardous pollutants but ordinary electrochemical reactors are used having electrodes with equal surfaces that can not only promote the oxidation reaction of the pollutants, thus implicitly generating reduced forms of them which themselves constitute potential polluting agents. The major advantage of the installation presented in the paper is the use of the electrochemical reactor with asymmetrical current densities, which is especially favoring the anodic electrooxidation reactions by using an anode with a significantly larger surface area than the cathode. This constructive aspect ensures a high efficiency of inactivation of cytotoxic pollutants compared to a regular electrochemical reactor. Compared to the classical methods, the electrochemical methods are much more eco-friendly [9].

\section{RESULTS AND DISCUSSIONS}

The experimental installation designed by our group, consists of three distinct parts: the electrochemical reactor with asymmetric current densities, hydraulic part and the automation devices [10]. Figure 1 presents the scheme of experimental installation depicted at large in the experimental section. The ifosfamide contaminated wastewater from tank-14 is fed inside the electrochemical reactor-1. The electrochemical reactions takes place for about 30 minutes, during which samples are being collected from time to time and analyzed by HPLC in order to determine ifosfamide contents. After reaction completion, the treated ifosfamide wastewater is placed in tank-17. The experiment involved several runs, using an artificial sample with predefined ifosfamide content (50 mg/dL) and samples of urine from patients under the cytostatic therapy. 


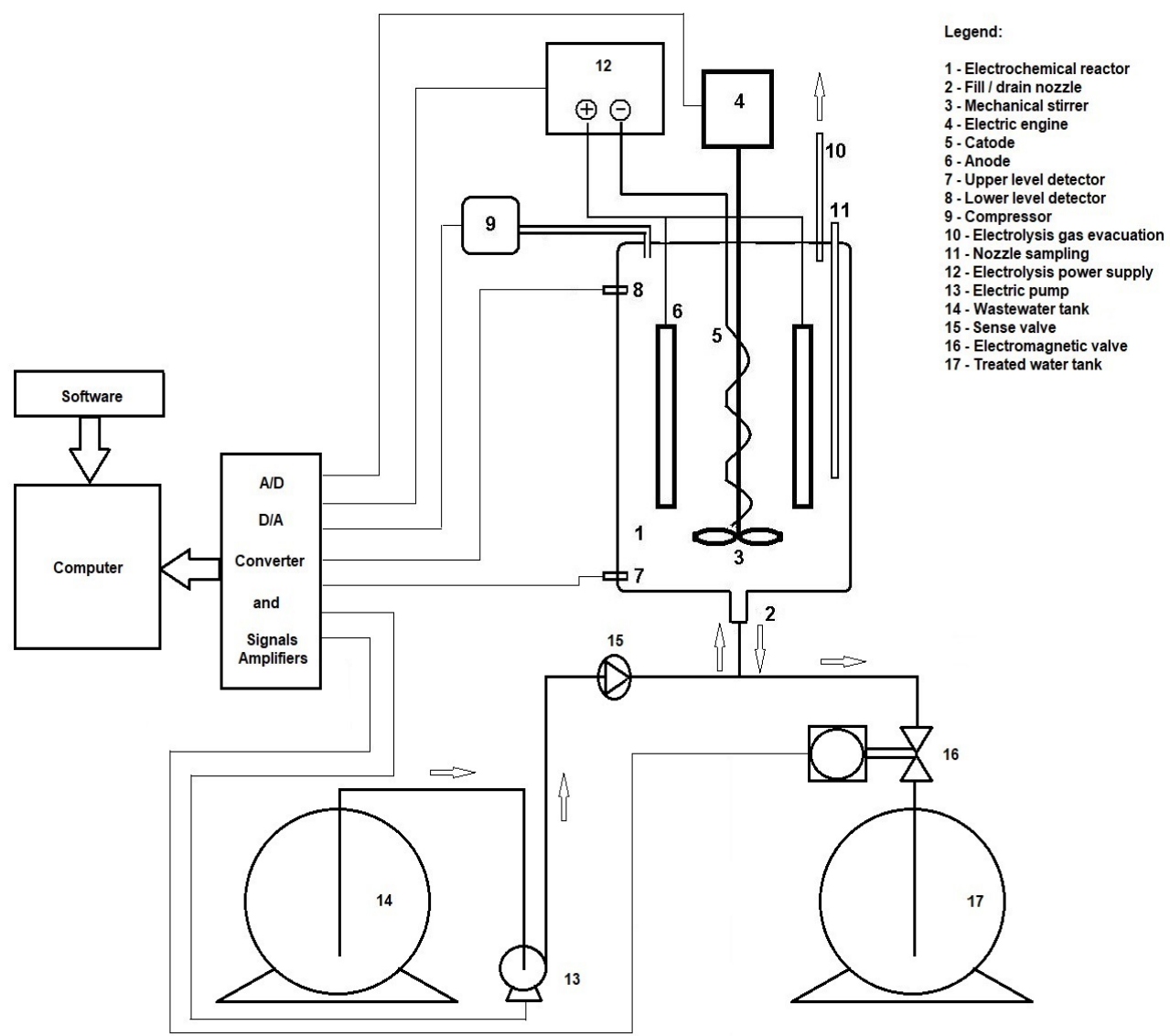

Figure 1. The simplified scheme of laboratory-scale ifosfamide wastewater depuration installation

The evolution of the ifosfamide concentration during treatment of artificial wastewater and the urine samples from the ten patients is presented in Table 1. The ifosfamide concentration is gradually decreasing until dropping below the limit of detection (LOD) of the HPLC detector in about 30 minutes. The calculated values for the detection and quantification limits were: $L O D=0.05$ $\mathrm{mg}$ ifosfamide/dL, and $\mathrm{LOQ}=2.54 \mathrm{mg}$ ifosfamide $/ \mathrm{dL}$. 
VALENTIN ORDODI, ANA-MARIA PANĂ, ALINA DUMITREL, DANIEL HĂDĂRUGĂ, ANDRA TĂMAȘ, VASILE PODE, ANAMARIA TODEA, VIRGIL PĂUNESCU, ȘERBAN NEGRU

Table 1. Evolution of ifosfamide concentration during electrochemical treatment for synthetic and urine samples

\begin{tabular}{|c|c|c|c|c|c|c|c|c|c|}
\hline Time (min) & 0 & 1 & 2 & 3 & 4 & 5 & 10 & 15 & 30 \\
\hline $\begin{array}{c}\text { Ifosfamide } \\
\text { artificial } \\
\text { sample } \\
\text { [mg/dL] }\end{array}$ & 50 & 35 & 27 & 20.5 & 14 & 12 & 3 & 0.3 & - \\
\hline $\begin{array}{c}\text { Sample 1 } \\
\text { [mg/dL] }\end{array}$ & 32 & 24 & 19 & 14 & 11 & 9 & 0.6 & 0.2 & - \\
\hline $\begin{array}{c}\text { Sample 2 } \\
\text { [mg/dL] }\end{array}$ & 43.5 & 33 & 26.5 & 19 & 14.5 & 11.5 & 0.8 & 0.3 & - \\
\hline $\begin{array}{c}\text { Sample 3 } \\
\text { [mg/dL] }\end{array}$ & 30 & 22 & 17 & 12.5 & 10 & 8 & 0.6 & 0.2 & - \\
\hline $\begin{array}{c}\text { Sample 4 } \\
\text { [mg/dL] }\end{array}$ & 32 & 24 & 18.5 & 13.5 & 10 & 7 & 0.6 & 0.3 & - \\
\hline $\begin{array}{c}\text { Sample 5 } \\
\text { [mg/dL] }\end{array}$ & 42 & 31 & 25 & 18 & 14 & 11 & 0.7 & 0.2 & - \\
\hline $\begin{array}{c}\text { Sample 6 } \\
\text { [mg/dL] }\end{array}$ & 41 & 31 & 23 & 16.5 & 12 & 10 & 0.7 & 0.4 & - \\
\hline $\begin{array}{c}\text { Sample 7 } \\
\text { [mg/dL] }\end{array}$ & 54 & 40 & 32 & 23 & 18 & 14 & 1 & 0.3 & - \\
\hline $\begin{array}{c}\text { Sample 8 } \\
\text { [mg/dL] }\end{array}$ & 36 & 27 & 22 & 16 & 12.5 & 9.5 & 0.6 & 0.2 & - \\
\hline $\begin{array}{c}\text { Sample 9 } \\
\text { [mg/dL] }\end{array}$ & 24 & 18 & 14 & 10.5 & 8 & 6.5 & 0.4 & 0.1 & - \\
\hline $\begin{array}{c}\text { Sample 10 } \\
\text { [mg/dL] }\end{array}$ & 36 & 26 & 21 & 15 & 11.5 & 9 & 0.7 & 0.3 & - \\
\hline
\end{tabular}

Figure 2 shows the variation of ifosfamide concentration from artificial sample during electrochemical depuration process obtained by regression curve. From the analysis of the experimental data it is observed that 15 minutes are sufficient for the inactivation of synthetic wastewater and 10 minutes for urine samples (ifosfamide concentration decreases below LOQ in all samples). From the chart, it can be noticed that the decreasing in ifosfamide concentration during electrochemical process follows an exponential equation (1) obtained by regression curve:

$$
C_{\text {ifosfamide }}=61,54 \cdot e^{-0,36 \cdot t}
$$






Figure 2. Variation of ifosfamide concentration from artificial wastewater during electrochemical depuration

The correlation coefficient $\left(R^{2}=0,994\right)$ indicates that equation (1) fits very well the evolution of ifosfamide concentration from synthetic wastewater during the electrochemical process of treatment $[11,12]$.

Ifosfamide is a cyclophosphamide isomer, having one of the $\mathrm{N}$-chloroethyl substituents moved to the nitrogen atom from the oxazophosphoric ring. The mechanism of action is similar to that of cyclophosphamide. From the pharmacokinetic data it is found that the bioavailability of the product is $100 \%$, the half-life is $5-6$ hours, and the renal elimination is $50 \%$ unchanged. Ifosfamide is administrated in patients in high doses of $2-3 \mathrm{~g} / \mathrm{m}^{2}$ body surface area per day in bone marrow transplantation procedure.

Experimental data show that this electrochemical method is efficient for purifying wastewater with ifosfamide content. The operating parameters of the electrochemical treatment device have been optimized through a series of preliminary experiments. The concentration of $5 \% \mathrm{NaCl}$ solution was optimal in terms of the speed of the electrochemical process, under the conditions in which it was desired to minimize the amount of reagents used. Also the intensity of the electrolysis current of $1 \mathrm{~A}$ ensures a reasonable speed of inactivation of the cytotoxic agent, avoiding an excessive heating of the electrolyte that 
VALENTIN ORDODI, ANA-MARIA PANĂ, ALINA DUMITREL, DANIEL HĂDĂRUGĂ, ANDRA TĂMAȘ, VASILE PODE, ANAMARIA TODEA, VIRGIL PĂUNESCU, ȘERBAN NEGRU

would generate harmful vapors and would require the existence of a cooling system that would increase the total energy consumption of the installation. The most likely mechanism of this degradation is presented by the sequence of reactions shown in Figure 3.<smiles>O=P1(NCCCl)OCCCN1CCCl</smiles>

( 2-chloroethyl) -[3-2-chloroethyl)

-2-oxo[1,3,2]oxazaphosphinan-2-yl]amine<smiles>CCCOP(=O)(NCCCl)NCCCl</smiles>

3-[bis( 2-chloroethylamino) -phosphoryloxy] -propionic acid

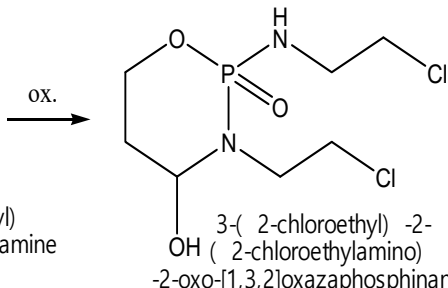

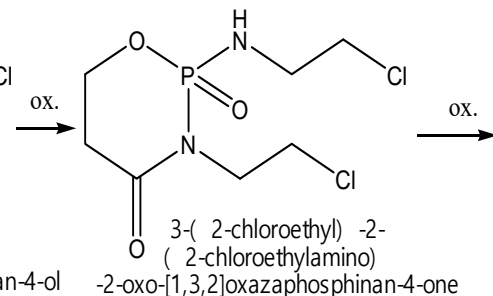
-2-oxo-[1,3,2]oxazaphosphinan-4-ol

-2-oxo-[1,3,2]oxazaphosphinan-4-one<smiles>O=[R10](O)OCCNP(=O)(O)OCCC(=O)O</smiles><smiles>NCCCl</smiles>

2-chloroethylamine

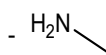
-hydroxyphosphoryloxy]<smiles></smiles><smiles>CC(CC(=O)O)C(=O)O</smiles><smiles>CC1([Tl])CCCCC1</smiles>
$\mathrm{CO}_{2}+\mathrm{H}_{2} \mathrm{O}$
$\mathrm{CO}_{2}+\mathrm{NH}_{3}+\mathrm{H}_{2} \mathrm{O}+\mathrm{HCl}$

Figure 3. Degradation mechanism of ifosfamide by electrochemical oxidation 
From the analysis of the experimental data obtained from the depuration of the urine samples from the 10 patients it is observed that they are very close to the theoretical regression curve calculated using the equation (1) and shown in Figure 4. This confirms that the proposed electrochemical method can be successfully applied to any urine sample containing ifosfamide within the specified concentration range.

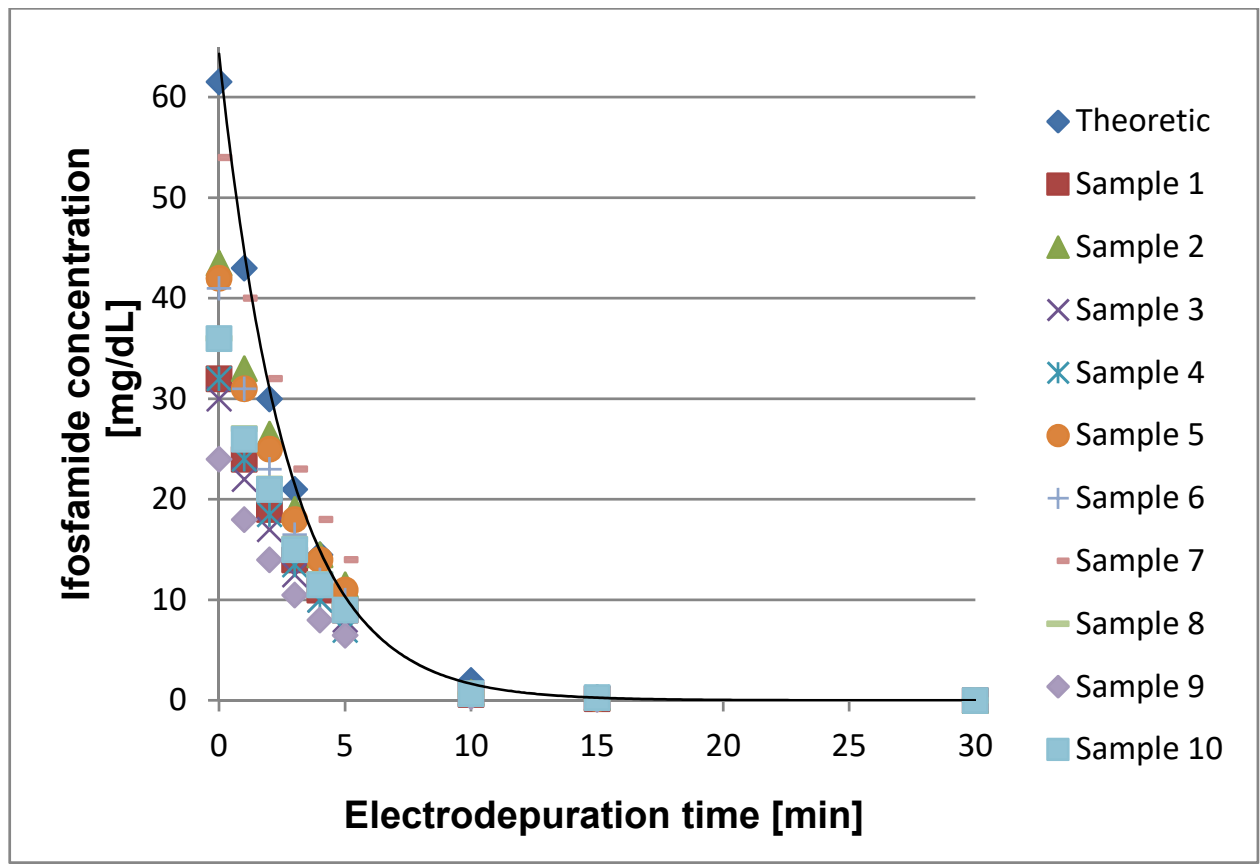

Figure 4. Experimental data obtained during electrochemical depuration of ten urine samples vs. theoretical model applied on the synthetic sample.

The yield of the electrochemical degradation (2) was calculated using the initial average concentration $\left(C_{i}\right)$ of the ten urine samples before the electrochemical treatment and the final average concentration $\left(C_{f}\right)$ after 10 minutes of degradation treatment (value below LOQ), right before the concentrations drops below the limit of detection. Equation (2) displays the average calculated yield for the electrochemical method of ifosfamide wastewater treatment using average concentrations of the real urine samples:

$$
\eta_{\text {ifosfamide }}=100-\frac{C f}{C_{i}} * 100=99.33 \%
$$


VALENTIN ORDODI, ANA-MARIA PANĂ, ALINA DUMITREL, DANIEL HĂDĂRUGĂ, ANDRA TĂMAȘ, VASILE PODE, ANAMARIA TODEA, VIRGIL PĂUNESCU, ȘERBAN NEGRU

\section{CONCLUSIONS}

The proposed electrochemical method and the experimental installation presented are very well suited for treatment of wastewater with ifosfamide content from medical institutions with an oncological profile. The use of electrochemical reactors with asymmetric current densities represents an ecological method of treatment of these wastewaters, as their products are mostly compounds with reduced impact onto environment in the given concentrations.

\section{EXPERIMENTAL SECTION}

\section{Description of the experimental installation and the operating mode}

The experimental installation consists of: the electrochemical reactor with asymmetric current densities, tanks for sample storage and related pumps and the automation devices [10]. Figure 1 presents the scheme of the laboratory-scale experimental installation.

The most important part of the experimental installation is the electrochemical reactor with asymmetric current densities (fig. 1 - 1), made up of a plexiglass container with a useful volume of $100 \mathrm{~cm}^{3}$, with a filling / draining nozzle at the bottom (fig. 1 - 2), a mechanical stirrer (fig. 1 - 3), operated by an electric micro-motor (fig. 1 - 4). The cathode of the reactor (fig. 1 - 5) is constructed from a stainless steel wire spiraled around the shaft of the mechanical stirrer with a diameter of $1 \mathrm{~mm}$ and a length of $115 \mathrm{~mm}$, having a working surface of $3.6 \mathrm{~cm}^{2}$. The anode (fig. $1-6$ ) is made of 8 graphite bars connected in parallel from an electrical point of view, with a total usable area of $45.2 \mathrm{~cm}^{2}$. Under the experimental conditions presented in this paper, the anodic current density is $220 \mathrm{~A} / \mathrm{m}^{2}$, while the cathodic current is 2700 $\mathrm{A} / \mathrm{m}^{2}$. The power supply of the electrochemical reactor (fig. 1 - 12) generates a constant current $(1 \mathrm{~A})$ throughout the electrolysis thus maintaining the kinetic constant of the electrochemical process. To remove the gases resulting from the electrochemical process, the reactor is continuously purged with compressed air $\left(100 \mathrm{~cm}^{3} / \mathrm{min}\right.$ ) generated by a microcompressor (fig. 1 - 9) and discharged out of the laboratory through the corresponding nozzle (fig. 1 - 10). For sampling of the reaction mass for physico-chemical analyses, the reactor is provided with a nozzle valve (fig. 1 - 11). The reactor is provided at the top and bottom respectively with two level sensors (fig. $1-7,8$ ) through which the electric pump is controlled during the filling of the reactor, respectively the electromechanical valve 
for draining [11]. The hydraulic part includes the wastewater tank (fig. 1 - 14) with the volume of $2 \mathrm{~L}$ from which the water is fed to the reactor using an electric pump (fig. 1 - 13). In order to avoid water leakage back, a sense valve is mounted on the hydraulic path immediately after the pump. The purified waste water is evacuated from the reactor by means of the electromechanical valve (fig. 1 - 16), in a storage tank of $2 \mathrm{~L}$ capacity (fig. 1 - 17).

The automation device includes an acquisition board (LabJak U3) with appropriate amplifiers for all signals, a laptop, and custom made software. This device controls the filling and emptying of the reactor by means of level sensors, the electric pump and the electromechanical valve, as well as the duration of the electrolysis by controlling the power supply of the electrochemical reactor. Additionally, this device controls the operation of the mechanical agitator and the compressor for the exhaust gases resulting during the electrochemical process $[14,15]$.

\section{Depuration of Ifosfamide contaminated wastewater}

For these experiments, urine samples were collected from 10 patients treated for various malignant lymphomas. The administered doses were in the range $3.4-5.1$ grams ifosfamide in 24 hours. Of this, about $50 \%$ is eliminated unchanged by the kidneys and along the urine of the respective patients the environment is contaminated.

The medium concentration of ifosfamide in the analyzed samples was $37 \mathrm{mg} / \mathrm{dL}$ in the salefied urine $(5 \% \mathrm{NaCl})$. An artificial ifosfamide wastewater with a concentration of $50 \mathrm{mg} / \mathrm{dL}$ ifosfamide in $5 \% \mathrm{NaCl}$ solution was also prepared and compared against the real samples. Depuration duration was 30 minutes for all samples including the artificial waste water, at electrolysis constant current $1 \mathrm{~A}[16,17,18]$.

For the collection of urine samples, each patient completed and signed an informed consent and obtained the approval of the Bioethics Commission of the University of Medicine and Pharmacy "V. Babeș" Timișoara.

Ifosfamide concentrations were measured using a high performance liquid chromatography (HPLC) - Agilent 1100 system equipped with a spectrophotometric detector. The analysis conditions were as follows: mobile phase acetonitrile : water $=20: 80$. The $\mathrm{pH}$ of the samples was adjusted to 5 with phosphate buffer. The mobile phase flow rate was constant: $1 \mathrm{~mL} / \mathrm{min}$. A $20 \mu \mathrm{L}$ sample was injected into a C18 Zorbax SB column at $25^{\circ} \mathrm{C}$ temperature. The spectrophotometric detector was set at $373 \mathrm{~nm}$. The acquisition time was 10 minutes for each sample $[19,20]$. Prior to HPLC analysis, all samples were treated with a $5 \%$ sodium thiosulphate solution ( $100 \mu \mathrm{L}$ to $900 \mu \mathrm{L}$ sample) to neutralize traces of free chlorine and kept in the refrigerator until analysis. 
VALENTIN ORDODI, ANA-MARIA PANĂ, ALINA DUMITREL, DANIEL HĂDĂRUGĂ, ANDRA TĂMAȘ, VASILE PODE, ANAMARIA TODEA, VIRGIL PĂUNESCU, ȘERBAN NEGRU

To determine the concentration of ifosfamide in the studied samples, both synthetic residual water with ifosfamide content and urine samples from patients, a calibration curve was constructed using ifosfamide ( $\geq 98 \%)$ purchased from Sigma-Aldrich, in the concentration range 0,1-50 mg/ dl. For all concentrations, three determinations were made. Figure 5 shows graphically the average values of the areas corresponding to the peaks of ifosfamide for each concentration.

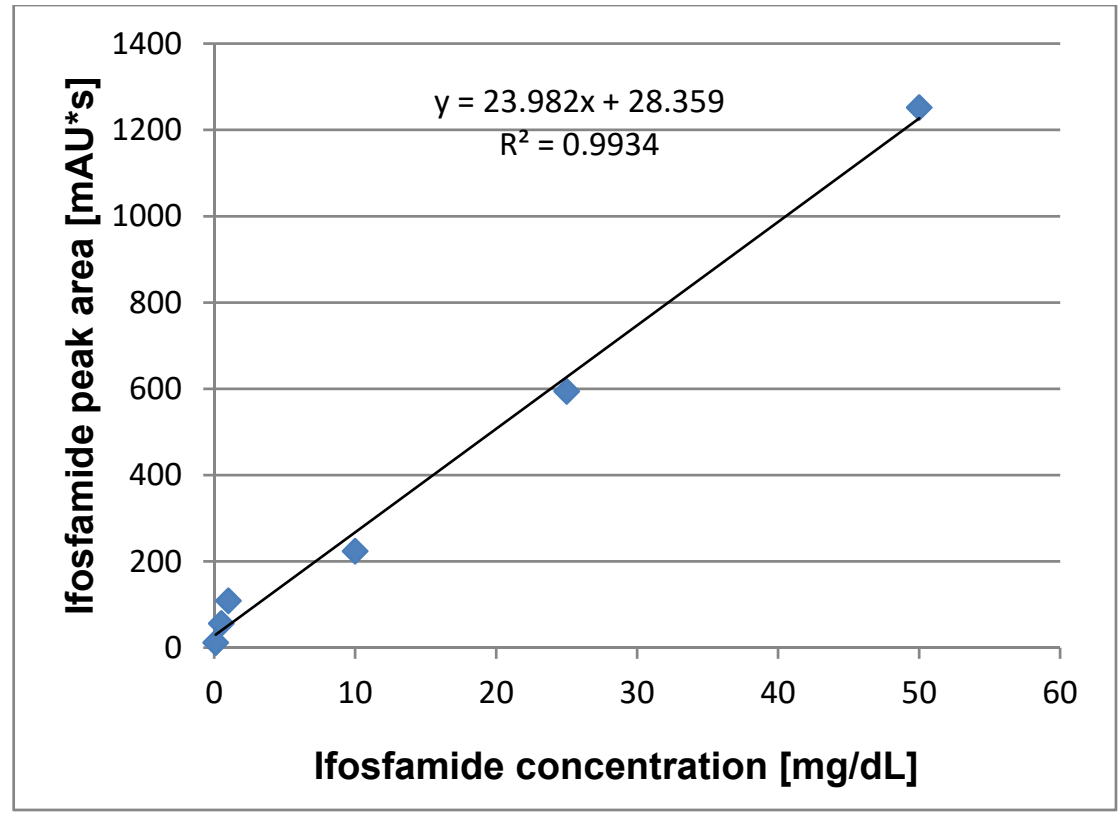

Figure 5. Ifosfamide HPLC calibration curve

The limit of detection (LOD) and the limit of quantification (LOQ) were estimated with the following mathematical relations:

$$
L O D=\frac{(3,3 \cdot S D)-\text { intercept }}{\text { slope }}
$$

and

$$
L O Q=\frac{(10 \cdot S D)-\text { intercept }}{\text { slope }}
$$


AN ECOLOGICAL TREATMENT METHOD FOR IFOSFAMIDE CONTAMINATED WASTE WATER RESULTING FROM ONCOLOGICAL THERAPY

\section{REFERENCES}

1. S. Hellweg, B. Thomas, H. K. Hungerbühler, "Modeling waste incineration for lifecycle inventory analysis in Switzerland. Environmental Modeling and Assesment", Kluwer Academic Publishers, 2001.

2. E. A. Cociş, V. F. Soporan, P. llea, F. Imre-Lucaci, B. M. Soporan, P. Bere, O. Nemeş, Studia UBB Chemia, 2012, LVII, 2, 147.

3. International Agency for Research on Cancer, "IARC Monograph on the Evaluation of Carcinogenic Risks to Humans: List of IARC Evaluations" IARC Lyon, France, 1996.

4. M.Ikematsu, K. Kaneda, M. Iseki, M. Yasuda, Sci. Total Environm., 2007, 382, 159-164.

5. F.I Badulescu, V. Voicu, L. Pop, A. Badulescu, "Vademecum de chimioterapie antineoplazica", Editura Medicala, Bucuresti, 1999.

6. N. Ghilezan, "Oncologie Generala", Editura Medicala, Bucuresti, 1982.

7. M.C. Mirica, "Reactoare electrochimice cu densități de curent asimetrice", Teză de doctorat, Craiova, 2005.

8. K. Yoshida, "Electrooxidation in Organic Chemistry", Krieger Publishing Company, Malabar Florida 1993.

9. S. Fogarasi, F. Imre-Lucaci, A. Ghirişan, B. R. H. Mişca, A. Imre-Lucaci, Studia UBB Chemia, 2016, LXI(3), 145.

10. D. J. Pickett, "Electrochemical reactor design", Elsevier, Amsterdam, 1979.

11. A. Nichici, E. Cicală, R. Mee, "Prelucrarea datelor experimentale. Curs şi aplicaţii", Centrul de multiplicare, Timişoara, 1996.

12. G.A. Brusturean, T. Todinca, D. Perju, J. Carre, Environm. Technol, 2007, 28(10), 1153-1162.

13. V. Ordodi, G.A. Dumitrel, A. Gruia, M. lacob, A. F. Mic, G. Jinescu, D. Perju, Revista de Chimie (Bucharest), 2010, 61(9), 857-861.

14. J. Hirose, F. Kondo, T. Nakano, T. Kobayashi, N. Hiro, Y. Ando, H. Takenaka, K. Sano, Chemosphere, 2005, 60, 1018-1024.

15. M. Ikematsu, K. Kaneda, M. Iseki, M. Yasuda, Sci. Total Environm., 2007, 382, 159-164.

16. S. Hansel, M. Castegnaro, M. H. Sportouch, M. De Meo, J. C. Milhavet, M. Laget, G. Dumenil, Int. Arch. Occup. Environm. Health, 1997, 69, 109-114.

17. A. Oprisoni, S. Arghirescu, C. Jinca, L. Balint-Gib, A. Isac, V. Ordodi, M. Baica, G. Doros, M. Serban. Abstracts of the $36^{\text {th }}$ Annual Meeting of the European Group for Blood and Bone Marrow Transplantation, Bone Marrow Transplantation, 2010, 45, S78-S327.

18. B. B. Park, W. S. Kim, H. S. Eom, J. S. Kim, Y. Y. Lee, S. J. Oh, D. H. Lee, C. Suh, Invest New Drugs, 2011, 29, 154-160.

19. R. R. Larson, M. B. Khazaeli, H. K. Dillon, Applied Occupational and Environmental Hygiene, 2003, 18(2), 109-119.

20. J.J. Kirkland, L.R.Synder, "Introduction to Modern Liquid Chromatography", $2^{\text {nd }}$ Edition, Jon Wiley and Sons, New York, 1979. 
